\title{
Shear Stiffness of 4 Common Intracranial Tumors Measured Using MR Elastography: Comparison with Intraoperative Consistency Grading
}

\author{
(D) N. Sakai, (D). Takehara, (D). Yamashita, (D) N. Ohishi, (D). Kawaji, (D). Sameshima, (D). Baba, (D). Sakahara, and (DH. Namba
}

\begin{abstract}
BACKGROUND AND PURPOSE: The stiffness of intracranial tumors affects the outcome of tumor removal. We evaluated the stiffness of 4 common intracranial tumors by using MR elastography and tested whether MR elastography had the potential to discriminate firm tumors preoperatively.
\end{abstract}

MATERIALS AND METHODS: Thirty-four patients with meningiomas, pituitary adenomas, vestibular schwannomas, and gliomas scheduled for resection were recruited for MR elastography. On the elastogram, the mean and the maximum shear stiffnesses were measured by placing an ROI on the tumor. Blinded to the MR elastography findings, surgeons conducted qualitative intraoperative assessment of tumor consistency by using a 5-point scale. Histopathologic diagnosis was confirmed by using the resected specimens. The mean and maximum shear stiffnesses were compared with histopathologic subtypes, and the intraoperative tumor consistency was graded by the surgeons.

RESULTS: The mean and maximum shear stiffnesses were the following: $1.9 \pm 0.8 \mathrm{kPa}$ and $3.4 \pm 1.5 \mathrm{kPa}$ for meningiomas, $1.2 \pm 0.3 \mathrm{kPa}$ and $1.8 \pm 0.5 \mathrm{kPa}$ for pituitary adenomas, $2.0 \pm 0.4 \mathrm{kPa}$ and $2.7 \pm 0.8 \mathrm{kPa}$ for vestibular schwannomas, and $1.5 \pm 0.2 \mathrm{kPa}$ and $2.7 \pm 0.8 \mathrm{kPa}$ for gliomas. The mean and maximum shear stiffnesses for meningiomas were higher than those of pituitary adenomas $(P<.05)$. The mean and maximum shear stiffnesses were significantly correlated with the surgeon's qualitative assessment of tumor consistency $(P<.05)$. The maximum shear stiffness for 5 firm tumors was higher than that of nonfirm tumors $(P<.05)$.

CONCLUSIONS: MR elastography could evaluate intracranial tumors on the basis of their physical property of shear stiffness. MR elastography may be useful in discriminating firm tumors preoperatively.

ABBREVIATIONS: MRE = MR elastography; $\mathrm{MEG}=$ motion-encoding gradient; ${ }_{\max } \mathrm{SS}=$ maximum shear stiffness; mean $\mathrm{SS}=$ mean shear stiffness

M any histopathologic processes in tumors, for example cell proliferation, angiogenesis, fibrosis, calcification, necrosis, and cyst formation, cause marked changes in the viscoelastic properties of tissue. Therefore, physicians have used palpation of the body to detect tumors in daily clinical settings. Regarding intracranial tumors, however, there is no clinical precedent for tumor stiffness. Only neurosurgeons have had the privilege of palpating intracranial tumors at the time of tumor resection. The

Received August 6, 2015; accepted after revision April 11, 2016.

From the Departments of Neurosurgery (N.S., H.K., T.S., H.N.), Radiology (Y.T., N.O.), Diagnostic Radiology and Nuclear Medicine (S.Y., H.S.), and Diagnostic Pathology (S.B.), Hamamatsu University Hospital, Hamamatsu, Japan. Naoto Sakai and Yasuo Takehara contributed equally to this study. Please address correspondence to Naoto Sakai, MD, PhD, Department of Neurosurgery, Hamamatsu University School of Medicine, 1-20-1, Handayama, Higashi-ku, Hamamatsu 431-3192, Japan; e-mail: nsakaineurosurg@gmail.com

- Indicates open access to non-subscribers at www.ajnr.org

http://dx.doi.org/10.3174/ajnr.A4832 degree of tumor stiffness or consistency is critical information for precise neurosurgical resection of intracranial tumors such as meningiomas, pituitary adenomas, and vestibular schwannomas, especially those surrounded by important neurovascular structures. Differences in histopathologic characteristics, namely meningothelial-versus-fibrous meningiomas, fibrous-versus-nonfibrous pituitary adenomas, Antoni A- versus Antoni B-dominant schwannomas, and high- versus-low-grade gliomas, might be correlated to the viscoelastic properties of intracranial tumors. Although conventional MR imaging and some other MR imaging sequences have been reported capable of predicting intracranial tumor consistency or fibrosis, they have not been used to directly assess the viscoelastic properties of tumors. ${ }^{1-3}$

MR elastography (MRE) is an emerging technology enabling the noninvasive assessment of the viscoelastic properties of tissues in vivo. ${ }^{4,5}$ MRE uses continuous shear waves generated by an extracorporeal mechanical wave driver, imaging the propagating shear waves with a phase-contrast MR 
image, and processing the wave images with an inversion algorithm to obtain a quantitative cross-sectional image of the shear stiffness map known as an elastogram. ${ }^{6}$ Since its first description by Muthupillai et al in $1995,{ }^{4}$ many clinical applications have been studied, especially for assessing liver disease. Multiple studies have demonstrated a strong correlation between MRE-measured hepatic stiffness and the stage of fibrosis at histology. MRE can serve as a more accurate alternative to invasive biopsy, which has been the criterion standard for the diagnosis and staging of liver fibrosis. ${ }^{7}$ Although MRE is not common in a neurologic setting, a series of attempts have been made to measure the stiffness of the brain affected by Alzheimer disease, ${ }^{8,9}$ multiple sclerosis, ${ }^{10}$ and normal-pressure hydrocephalus. ${ }^{11,12}$ As for intracranial tumors, only a few studies involving meningiomas and glioblastomas have been published. ${ }^{13,14}$ In these studies, a correlation between histopathologic characteristics and MRE has not been described in detail. The purposes of the present study were the following: 1) to evaluate tumor stiffness by using MRE in relation to the histopathology, and 2) to test whether MRE has the potential to discriminate firm tumor preoperatively.

\section{MATERIALS AND METHODS}

\section{Ethics}

Written informed consent was obtained from all patients in our institutional review board-approved study.
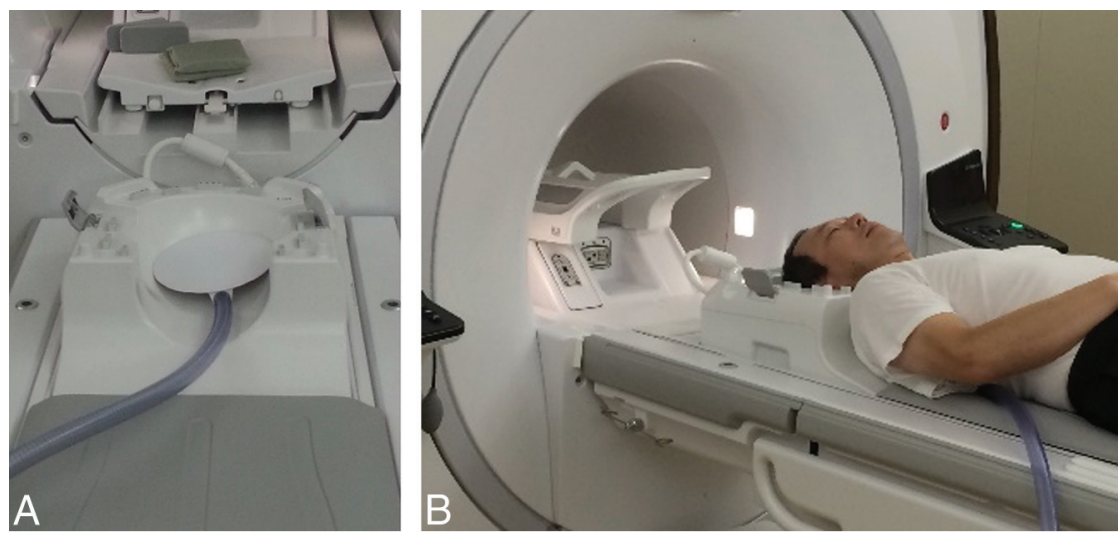

FIG 1. A passive pneumatic driver (MR Touch; GE Healthcare) was placed in a 12-channel phased array Neurovascular Array Coil (A). Shear waves were introduced in the brain by using this system (B).

\section{Patients}

Between September 2014 and June 2015, MR imaging examinations, including MRE, were performed on 34 consecutive patients (11 men and 23 women; mean age, 54 years; range, $31-77$ years) scheduled for resection with previously identified meningiomas, pituitary adenomas, vestibular schwannomas, and gliomas by using conventional MR imaging with contrast. All patients underwent microscopic surgery performed by experienced neurosurgeons at our university hospital. Blinded to the MRE results, surgeons graded tumor stiffness at the time of resection. The dominant tissue consistency was graded by using a 5-point scale previously reported by Murphy et al ${ }^{13}$ as follows: 1 , soft; 2 , mostly soft; 3, intermediate; 4 , mostly firm (at least $75 \%-80 \%$ of the tumor was firm and required ultrasonic aspiration at a high setting); and 5, firm (most of the tumor required ultrasonic aspiration at a maximum setting). We used an ultrasonic aspirator (Sonopet Ultrasonic Aspirator; Stryker, Kalamazoo, Michigan) when we could not resect tumors by using an air suction tube. In this study, tumors on the scale of 4 and 5 were defined as "firm," and tumors on the scale of 1-3 were defined as "nonfirm" by surgeons. All surgical procedures were recorded by using a digital video recorder (DATA Gen Pro; Seventh Dimension Design, Hyogo, Japan) and were reviewed for this assessment.

\section{MR Elastography}

MRE was performed by using a 3T clinical unit (Discovery MR750W; GE Healthcare, Milwaukee, Wisconsin) with a 12-channel phased array Neurovascular Array Coil (Medrad, Indianola, Pennsylvania). A passive pneumatic driver with a diameter of $19 \mathrm{~cm}$ was positioned underneath the occipital portion of the head. Shear waves were introduced in the brain by using the MR Touch system (GE Healthcare) (Fig 1). The imaging parameters for spin-echo echo-planar imagingbased MRE were as follows: TR, 1000 $\mathrm{ms}$; TE, $86.4 \mathrm{~ms}$; FOV, $24 \mathrm{~cm}$; bandwidth, $\pm 250 \mathrm{kHz} ; 64 \times 64$ matrix $(256 \times 256$ reconstruction matrix with zero-filled interpolation); and section

Table 1: Summary of patient histopathologic characteristics: meningiomas (13 cases)

\begin{tabular}{|c|c|c|c|c|c|c|}
\hline Age (yr)/Sex & Location & $\begin{array}{l}\text { Size } \\
(\mathrm{mm})\end{array}$ & $\begin{array}{c}\text { Mean Shear } \\
\text { Stiffness (kPa) }\end{array}$ & $\begin{array}{l}\text { Maximum Shear } \\
\text { Stiffness (kPa) }\end{array}$ & $\begin{array}{l}\text { Intraoperative Tumor } \\
\text { Consistency; Scale } 1 \sim 5\end{array}$ & $\begin{array}{l}\text { Histopathologic } \\
\text { Subtypes }\end{array}$ \\
\hline $44 / F$ & Parasagittal & 46 & 2.1 & 4.7 & 3 (not firm) & Meningothelial meningioma \\
\hline $57 / \mathrm{M}$ & Tuberculum sellar & 53 & 1.6 & 3.0 & 3 (not firm) & Meningothelial meningioma \\
\hline $68 / M$ & Parasagittal & 94 & 1.6 & 3.3 & 3 (not firm) & Anaplastic meningioma \\
\hline $67 / F$ & Convexity & 66 & 1.4 & 4.1 & 4 (firm) & Atypical meningioma \\
\hline $50 / F$ & Parasagittal & 23 & 2.2 & 3.8 & 5 (firm) & Transitional meningioma \\
\hline $40 / F$ & Cavernous sinus & 35 & 2.6 & 4.7 & 3 (not firm) & Meningothelial meningioma \\
\hline $52 / F$ & Convexity & 52 & 1.7 & 2.5 & 3 (not firm) & Atypical meningioma \\
\hline $58 / F$ & Petroclival & 20 & 1.2 & 1.6 & 3 (not firm) & Meningothelial meningioma \\
\hline $51 / \mathrm{F}$ & Sphenoid ridge & 28 & 1.8 & 2.4 & 3 (not firm) & Meningothelial meningioma \\
\hline $66 / F$ & $\mathrm{CP}$ angle & 51 & 4.4 & 7.2 & 4 (firm) & Fibrous meningioma \\
\hline $38 / F$ & Tuberculum sellar & 14 & 1.7 & 2.3 & 2 (not firm) & Meningothelial meningioma \\
\hline $38 / F$ & Petroclival & 23 & 1.2 & 1.8 & 2 (not firm) & Angiomatous meningioma \\
\hline $77 / M$ & Convexity & 25 & 1.7 & 2.6 & 2 (not firm) & Meningothelial meningioma \\
\hline
\end{tabular}

Note:-CP indicates cerebellopontine. 
thickness, $5 \mathrm{~mm}$. These acquisitions were performed with a single-shot, 1-signal average, 8 MRE time points, 10-13 sections, MRE motion-encoding in the through-plane direction; and no flow compensation or spatial presaturation. Parallel imaging (array spatial sensitivity encoding technique) was used with a reduction factor of 2. To optimize the motion-encoding gradient (MEG) frequency and the external driver frequency, we tested various MEG frequencies from $40-$ to $120-\mathrm{Hz}$ and from $40-$ to $120-\mathrm{Hz}$ driver frequencies at every $20 \mathrm{~Hz}$, otherwise under the same imaging conditions, on a healthy volunteer before commencement of this study. The images generated by using MRE included wave images, depicting the tissue motion, and stiffness images (elastograms).

The criteria for optimization were the presence of noninterfering parallel waves in the wave images, homogeneity of the stiffness distributions for the white matter of the cerebral and the cerebellar hemispheres, and the image signal-to-noise ratio. The previously reported stiffness values for normal white and gray matter were also compared with the measured values from the stiffness map. The red and blue stripes on the wave images show the mechanical waves propagating within the brain. The deepness of the colors reflects the wave amplitude, and their width indicates the wavelength. A longer wavelength reflects faster wave propagation in the media, which indicates higher elasticity of the tissue. The wave information is processed to produce $2 \mathrm{D}$ color-coded elastograms and 2D quantitative gray-scale elastograms. ROIs can be drawn on the gray-scale elastograms to measure the elasticity

Table 2: Pituitary adenomas (11 cases)

\begin{tabular}{|c|c|c|c|c|c|}
\hline $\begin{array}{c}\text { Age } \\
(y r) / \text { Sex }\end{array}$ & $\begin{array}{l}\text { Endocrinologic } \\
\text { Subtypes }\end{array}$ & $\begin{array}{l}\text { Size } \\
(\mathrm{mm})\end{array}$ & $\begin{array}{l}\text { Mean Shear } \\
\text { Stiffness (kPa) }\end{array}$ & $\begin{array}{l}\text { Maximum Shear } \\
\text { Stiffness (kPa) }\end{array}$ & $\begin{array}{l}\text { Intraoperative Tumor } \\
\text { Consistency; Scale 1 } \sim 5\end{array}$ \\
\hline $71 / \mathrm{F}$ & Nonfunctioning & 22 & 1.4 & 2.0 & 1 (not firm) \\
\hline $40 / F$ & GH producing & 27 & 1.0 & 1.7 & 1 (not firm) \\
\hline $47 / F$ & Nonfunctioning & 40 & 1.1 & 1.7 & 1 (not firm) \\
\hline $38 / \mathrm{M}$ & Nonfunctioning & 34 & 1.4 & 2.0 & 1 (not firm) \\
\hline $31 / \mathrm{F}$ & GH producing & 17 & 1.3 & 1.8 & 1 (not firm) \\
\hline $41 / \mathrm{F}$ & FSH producing & 17 & 0.9 & 1.1 & 1 (not firm) \\
\hline $57 / F$ & Nonfunctioning & 58 & 1.6 & 2.5 & 2 (not firm) \\
\hline $45 / M$ & Nonfunctioning & 24 & 0.6 & 0.8 & 1 (not firm) \\
\hline $71 / \mathrm{M}$ & Nonfunctioning & 39 & 1.0 & 1.6 & 3 (not firm) \\
\hline $63 / F$ & Nonfunctioning & 22 & 1.6 & 2.1 & 4 (firm) \\
\hline $38 / F$ & Nonfunctioning & 27 & 1.6 & 2.0 & 3 (not firm) \\
\hline
\end{tabular}

Note:-GH indicates growth hormone; FSH, follicle-stimulating hormone.

Table 3: Vestibular schwannomas (6 cases)

\begin{tabular}{lcccc}
\hline Age (yr)/Sex & $\begin{array}{c}\text { Size } \\
\mathbf{( m m )}\end{array}$ & $\begin{array}{c}\text { Mean Shear } \\
\text { Stiffness (kPa) }\end{array}$ & $\begin{array}{c}\text { Maximum Shear } \\
\text { Stiffness (kPa) }\end{array}$ & $\begin{array}{c}\text { Intraoperative Tumor } \\
\text { Consistency; Scale 1 5 }\end{array}$ \\
\hline $57 / \mathrm{F}$ & 28 & 1.7 & 2.5 & 2 (not firm) \\
$50 / \mathrm{F}$ & 33 & 2.5 & 3.3 & 3 (not firm) \\
$46 / \mathrm{F}$ & 16 & 1.6 & 2.0 & 3 (not firm) \\
$77 / \mathrm{F}$ & 24 & 2.2 & 3.2 & 3 (not firm) \\
$50 / \mathrm{M}$ & 21 & 1.5 & 1.7 & 2 (not firm) \\
$43 / \mathrm{M}$ & 34 & 2.2 & 3.7 & 4 (firm) \\
\hline
\end{tabular}

(typically reported in kilopascals). A cross-hatching pattern superimposed on the elastograms indicates less reliable areas for measurement of the elasticity based on the wave amplitude, the pattern of the waves in the wave images, and the signal-to-noise ratio of the magnitude images.

In this study, elastograms were qualitatively assessed for the degree of image quality, such as the extent of signal loss, and quantitatively for the areas without cross-hatches. After determining the optimal motion-encoding gradient frequency, we also examined the external driver amplitudes, namely $50 \%$ versus $70 \%$. As a result, an MEG of $60 \mathrm{~Hz}$, an external driver frequency of $40 \mathrm{~Hz}$, and an amplitude of $50 \%$ were determined to be optimal in this settings. The choice of motion and MEG frequencies was determined subjectively during this optimization process. The acquisition time for MRE was 50 seconds at most.

\section{Conventional MR Imaging}

Conventional MR imaging with contrast media and arterial spinlabeled perfusion imaging were also performed in the current study to correctly demarcate the tumor area, which became the reference when ROI placement on the elastogram was performed. The imaging parameters have been described previously. ${ }^{14-18}$

\section{Stiffness Measurement on MR Elastogram}

The signal intensity reflects the stiffness on each elastogram. For the measurement of tumor stiffness, the largest possible ROI was placed on the tumors by avoiding the interference fringes on the wave image and cross-hatches on the stiffness map. The mean shear stiffness $\left({ }_{\text {mean }} \mathrm{SS}\right)$ and the maximum shear stiffness $\left({ }_{\max } \mathrm{SS}\right)$ were measured in kilopascals. Because the anatomic boundary of the tumor was difficult to discern on the stiffness map alone, T2-weighted axial images, fat saturated T1-weighted images obtained pre- and postcontrast administration, and the axial diffusion-weighted image of the corresponding sections with the stiffness map of the corresponding section were also simultaneously displayed. ROIs ranging from 79 to 1874 pixels were drawn freehand on the workstation display. If the tumor was partially covered by cross-hatches, lesion stiffness in the area without cross-hatches was measured. The measurements were repeated twice for each region, and the values were averaged.

Table 4: Gliomas (4 cases)

\begin{tabular}{llccccc}
\hline Age $(\mathbf{y r}) /$ Sex & Location & $\begin{array}{c}\text { Size } \\
(\mathbf{m m})\end{array}$ & $\begin{array}{c}\text { Mean Shear } \\
\text { Stiffness }(\mathbf{k P a})\end{array}$ & $\begin{array}{c}\text { Maximum Shear } \\
\text { Stiffness }(\mathbf{k P a})\end{array}$ & $\begin{array}{c}\text { Intraoperative Tumor } \\
\text { Consistency; Scale 1 } \mathbf{5}\end{array}$ & $\begin{array}{c}\text { Histopathologic } \\
\text { Subtypes }\end{array}$ \\
\hline 75/M & Frontal lobe & 32 & 1.2 & 2.4 & 1 (not firm) & Anaplastic astrocytoma \\
77/M & Cerebellum & 22 & 1.7 & 2.3 & 1 (not firm) & Glioblastoma \\
36/M & Frontal lobe & 65 & 1.4 & 3.8 & 2 (not firm) & Glioblastoma \\
61/F & Insula & 55 & 1.5 & 2.2 & 3 (not firm) & Glioblastoma \\
\hline
\end{tabular}



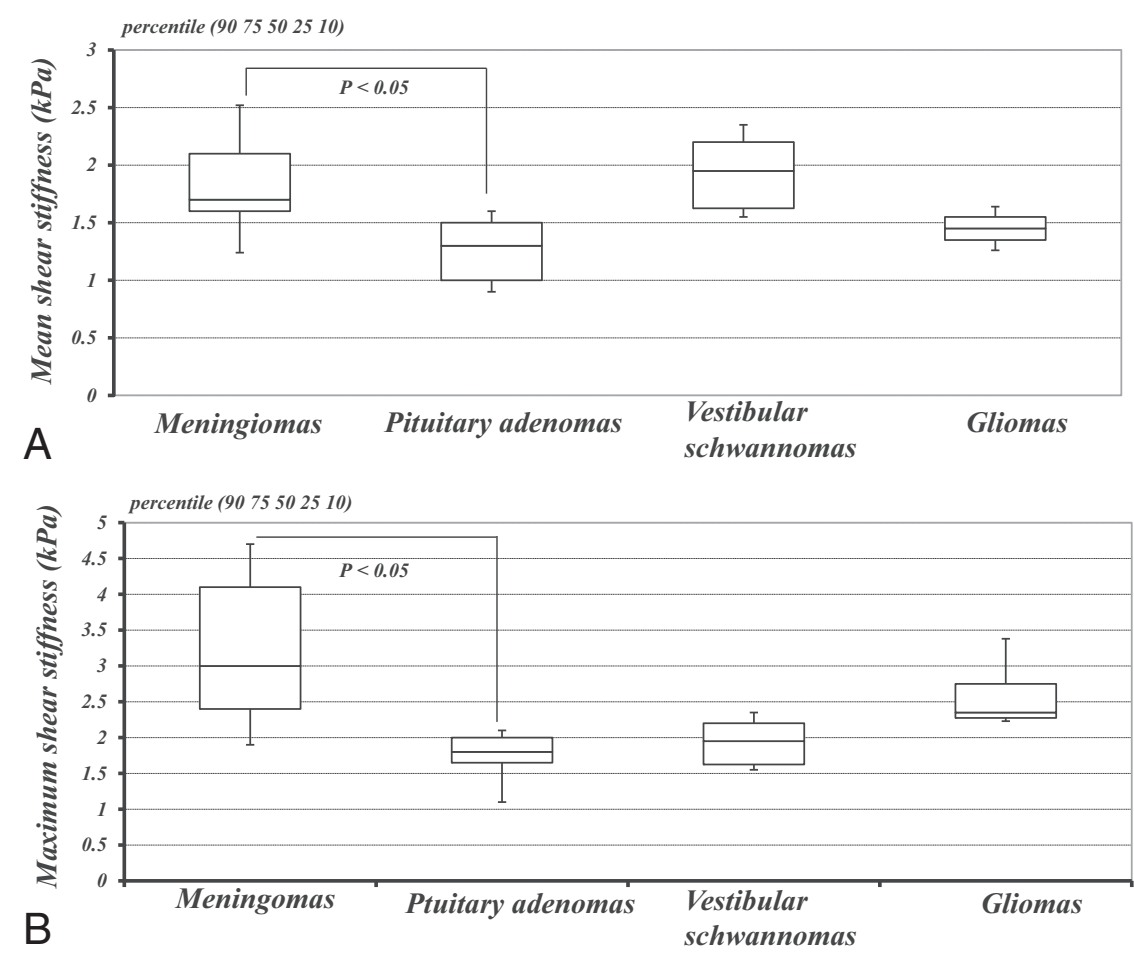

FIG 2. Comparison of the ${ }_{\text {mean }} \mathrm{SS}$ and ${ }_{\text {max }} \mathrm{SS}$ determined by using MRE among histopathologically variable intracranial tumors: 13 cases of meningiomas ( ${ }_{\text {mean }} \mathrm{SS}=1.9 \pm 0.8 \mathrm{kPa},{ }_{\max } \mathrm{SS}=3.4 \pm 1.5$ $\mathrm{kPa}$ ), 11 cases of pituitary adenomas (mean $\mathrm{SS}=1.2 \pm 0.3 \mathrm{kPa}$, max $\mathrm{SS}=1.8 \pm 0.5 \mathrm{kPa}$ ), 6 cases of vestibular schwannomas $\left({ }_{\text {mean }} \mathrm{SS}=2.0 \pm 0.4 \mathrm{kPa}\right.$, $\left.\max _{\mathrm{SS}}=2.7 \pm 0.8 \mathrm{kPa}\right)$, and 4 cases of gliomas ${ }_{\text {mean }} \mathrm{SS}=1.5 \pm 0.2 \mathrm{kPa}$, max $_{1} \mathrm{SS}=2.7 \pm 0.8 \mathrm{kPa}$ ). The ${ }_{\text {mean }} \mathrm{SS}$ and ${ }_{\text {max }} \mathrm{SS}$ of meningiomas were higher than those of the pituitary adenomas $(P<.05)$. Box-and-whisker plots show the mean $S S(A)$ and ${ }_{\max } \mathrm{SS}(B)$. The lower and upper hinges of the boxes denote the 25th and 75th percentiles, respectively. The median (50th percentile) of each distribution is indicated by the line. The whiskers on each side denote the 10th and 90th percentiles.

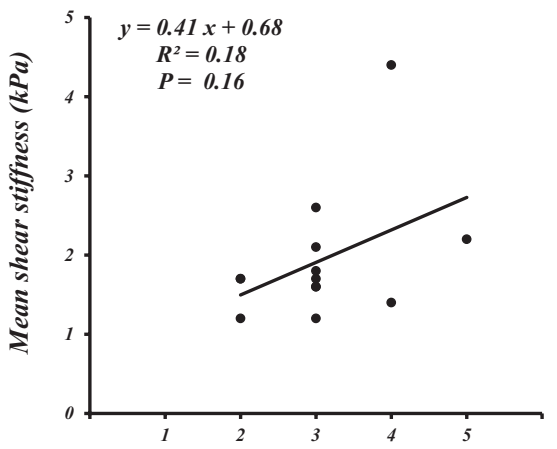

A

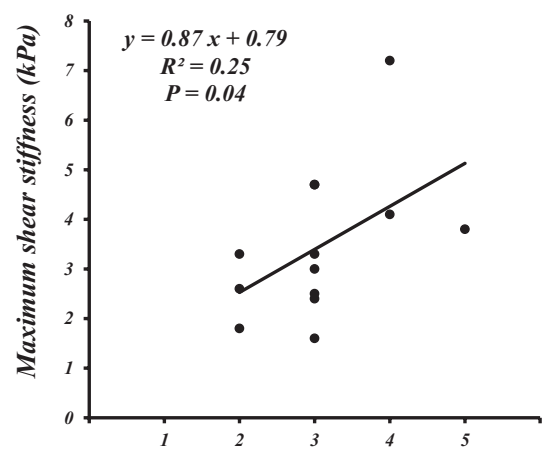

B Intraoperative tumor consistency

FIG 3. Scatterplot of the mean $\mathrm{SS}$ and ${ }_{\max } \mathrm{SS}(\mathrm{kPa})$ determined by using MRE and a 5-point scale of intraoperative qualitative assessment of tumor consistency in 13 patients with meningiomas. Although the mean SS did not significantly correlate with the grading $(A)$, significant correlations between the ${ }_{\text {max }} S \mathrm{~S}$ and the grading were obtained $(B)(P<.05)$ (Spearman rank order test).

\section{Histopathologic Evaluation}

Sections were stained with hematoxylin-eosin for routine histopathology. Immunohistochemical stains were also used for the following: epithelial membrane antigen and vimentin for meningiomas; adenocorticotrophic hormone, prolactin, growth hormone, luteinizing hormone, follicle-stimulating hormone, thyroid-stimulating hormone, and cytokeratin CAM5.2 for pituitary adenomas; S-100 for vestibular schwannomas; and glial fibrillary acidic protein, oligodendrocyte transcription factor (Olig2), anti-
O6-methylguanine methyltransferase, isocitrate dehydrogenase 1 , and p53 for gliomas. Additionally, Ki-67 was examined for all samples. On the basis of the results, an experienced pathologist (S.B.) determined the histopathologic diagnosis.

\section{Statistical Analysis}

The mean SS and max SS were compared among meningiomas, pituitary adenomas, vestibular schwannomas, and gliomas by using the Kruskal-Wallis $\mathrm{H}$ test following the Mann-Whitney $U$ test with Bonferroni correction. The correlations between the mean SS and ${ }_{\text {max }} \mathrm{SS}$ and a 5-point scale of intraoperative tumor consistency were examined by using the Spearman rank order test. The mean SS and ${ }_{\text {max }}$ SS were compared between the intraoperative firm tumors (intraoperative consistency scale, 4 and 5) and those that were nonfirm (intraoperative consistency scale, $1 \sim 3$ ) by using the MannWhitney $U$ test. Probability values of $<.05$ were considered significant. For the statistical analysis, the freely available software EZR (Saitama Medical Center, Jichi Medical University; http:// www.jichi.ac.jp/saitama-sct/SaitamaHP. files/statmed.html) was used.

\section{RESULTS}

The patient characteristics, tumor location, size, mean and maximum tumor shear stiffness assessed by using MRE, and the intraoperative tumor consistency in 34 patients are summarized by histopathologic subtypes in Tables 1-4.

The mean mean $\mathrm{SS}$ and ${ }_{\text {max }} \mathrm{SS}$ were as follows: $1.9 \pm 0.8 \mathrm{kPa}$ and $3.4 \pm 1.5 \mathrm{kPa}$, respectively, for 13 patients with meningiomas; $1.2 \pm 0.3 \mathrm{kPa}$ and $1.8 \pm 0.5 \mathrm{kPa}$, respectively, for 11 patients with pituitary adenomas; $2.0 \pm 0.4 \mathrm{kPa}$ and $2.7 \pm$ $0.8 \mathrm{kPa}$, respectively, for 6 patients with vestibular schwannomas; and $1.5 \pm 0.2$ $\mathrm{kPa}$ and $2.7 \pm 0.8 \mathrm{kPa}$, respectively, for 4 patients with gliomas. The ${ }_{\text {mean }} \mathrm{SS}$ and ${ }_{\max } \mathrm{SS}$ of meningiomas were higher than those of pituitary adenomas $(P<.05)$ (the Kruskal-Wallis $\mathrm{H}$ test following the MannWhitney $U$ test with Bonferroni correction) (Fig 2). Although the mean $\mathrm{SS}$ of meningiomas did not significantly correlate with the intraoperative grading (Fig $2 \mathrm{~A}$ ), significant correlations between the ${ }_{\text {max }}$ SS and the surgeon's qualitative assessment of tumor consistency were obtained $(P<.05)$ (Spearman rank order test) (Fig $3)$. Regarding all intracranial tumors, both the ${ }_{\text {mean }} \mathrm{SS}$ and $\max _{\text {max }} \mathrm{SS}$ 


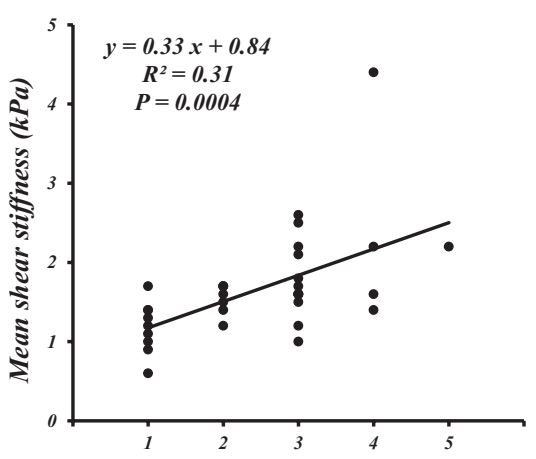

A Intraoperative tumor consistency

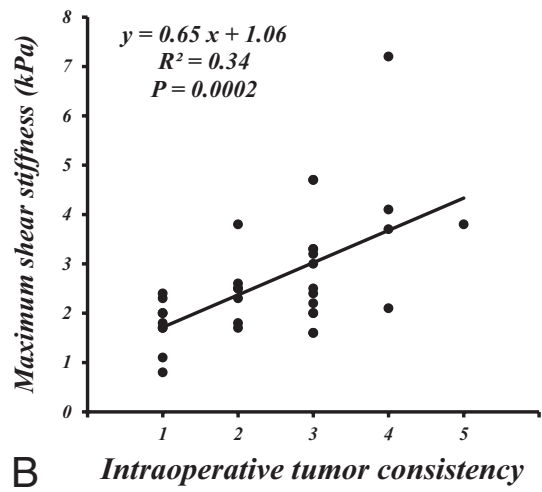

FIG 4. Scatterplot of the ${ }_{\text {mean }} \mathrm{SS}$ and ${ }_{\text {max }} \mathrm{SS}(\mathrm{kPa})$ determined by using MRE and a 5-point scale of intraoperative qualitative assessment of tumor consistency in 34 patients with 4 common intracranial tumors. Both the ${ }_{\text {mean }} \mathrm{SS}$ and ${ }_{\text {max }} \mathrm{SS}$ were significantly correlated with the surgeon's grading $(P<.05)$ (Spearman rank order test).
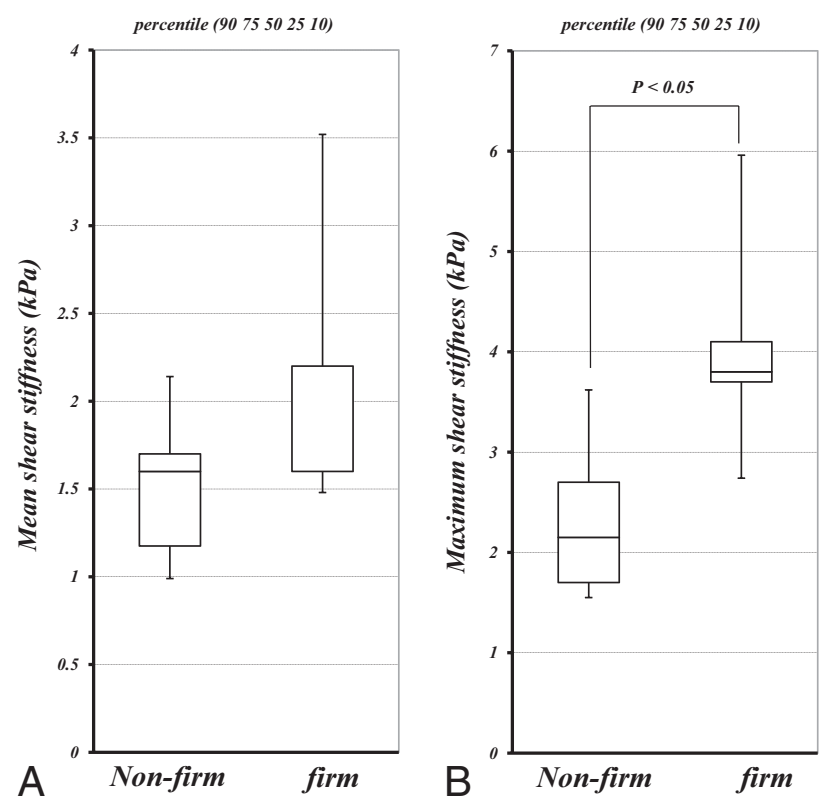

FIG 5. Comparison of the ${ }_{\text {mean }} \mathrm{SS}$ and ${ }_{\text {max }}$ SS was determined by using MRE among tumors with an intraoperative consistency scale of 1-3 that were nonfirm and those with a scale of 4 and 5 that were firm; there were 29 cases that were nonfirm $\left(_{\text {mean }} \mathrm{SS}=1.6 \pm 2.6 \mathrm{kPa}\right.$; ${ }_{\max } \mathrm{SS}=2.4 \pm 1.2 \mathrm{kPa}$ ) and 5 cases that were firm $($ mean $\mathrm{SS}=3.0 \pm 2.6$ $\mathrm{kPa} ;{ }_{\max } \mathrm{SS}=4.2 \pm 1.9 \mathrm{kPa}$ ). The ${ }_{\max } \mathrm{SS}$ values in firm tumors were higher than those in nonfirm tumors $(P<.05$; Mann-Whitney $U$ test). Box-and-whisker plots show the mean $S S(A)$ and ${ }_{\text {max }} S S(B)$. The lower and upper hinges of the boxes denote the 25th and 75 th percentiles, respectively. The median (50th percentile) of each distribution is indicated by the line. Whiskers on each side denote the 10th and 90th percentiles.

significantly correlated with the surgeon's grading $(P<.05)$ (Spearman rank order test) (Fig 4). In this study, 29 cases were nonfirm (intraoperative consistency scale, $1 \sim 3$ ), whereas 5 tumors were firm (intraoperative consistency scale, 4 and 5), requiring ultrasonic aspiration at high settings. The ${ }_{\text {mean }} \mathrm{SS}$ and ${ }_{\max } \mathrm{SS}$ of tumors that were not firm were $1.6 \pm 2.6 \mathrm{kPa}$ and $2.4 \pm 1.2 \mathrm{kPa}$, respectively. The mean $\mathrm{SS}$ and ${ }_{\text {max }} \mathrm{SS}$ of tumors that were firm were $3.0 \pm 2.6 \mathrm{kPa}$ and $4.2 \pm 1.9 \mathrm{kPa}$, respectively. Although the ${ }_{\text {mean }} \mathrm{SS}$ for the firm tumors was not significantly higher than that of tumors that were not firm, the ${ }_{\max }$ SS for the firm tumors was sig- nificantly higher than that of tumors that were not firm $(P<.05$, the MannWhitney $U$ test) (Fig 5).

Representative cases of a meningioma (case 44/female, right parasagittal meningothelial meningioma), a pituitary adenoma (case $41 /$ female, folliclestimulating hormone-producing adenoma), a vestibular schwannoma (case 51/male, left cerebellopontine angle), and a glioma (case 61/female, right insular glioblastoma) involving contrast-enhanced T1-weighted and T2weighted MRI, wave MRE images, elastograms, and hematoxylin-eosinstained sections (original magnification, $\times 100)$ are shown in Fig 6. Representative cases of firm tumors (case 51/male, left cerebellopontine angle fibrous meningioma; case 63/female, recurrent fibrous nonfunctioning pituitary adenoma) involving contrast-enhanced T1-weighted and T2-weighted MRI, wave MRE images, elastograms, and hematoxylin-eosin-stained sections (original magnification, $\times 100$ ) are shown in Fig 7.

\section{DISCUSSION}

In this study, we measured the shear stiffness of 4 major intracranial tumors, namely meningiomas, pituitary adenomas, vestibular schwannomas, and gliomas by using MRE. Murphy et $\mathrm{al}^{13}$ reported the stiffness of meningiomas. Regarding pituitary adenomas and vestibular schwannomas, this is the first study to describe the direct measurement of shear stiffness by using MRE, to our knowledge. In relation to gliomas, Streitberger et $\mathrm{al}^{14}$ reported that the mean shear stiffness of glioblastomas in 22 patients was $1.32 \pm 0.26 \mathrm{kPa}$; although the number of our glioma cases was small, the mean value of the shear stiffness was similar to their results. A significant difference was observed between the shear stiffness of meningiomas and that of pituitary adenomas. The result was compatible with our intraoperative impression of the consistency of these tumors during excision.

We have evaluated the dominant tissue consistency at tumor resection by using a 5 -point scale as previously reported by Murphy et al. ${ }^{13}$ They found that the relative shear stiffness assessed by using MRE in meningiomas ( 13 cases) was significantly correlated with the 5-point scale. Although we could not reveal a significant correlation between the mean SS and the grading, we have demonstrated the significant correlation between the ${ }_{\text {max }}$ SS and our stiffness grading. We presume that this was partially the result of the surgeon's judgment of tumor stiffness, in which the scoring tended to be dependent on the hardest portions. It is also presumed that the statistical significance was affected by our coarse spatial resolution, which averaged the stiffness of the tissue. Therefore, the maximum average stiffness result became significant, but the average stiffness was not the result of further averaging.

We also demonstrated significant correlation for both the 

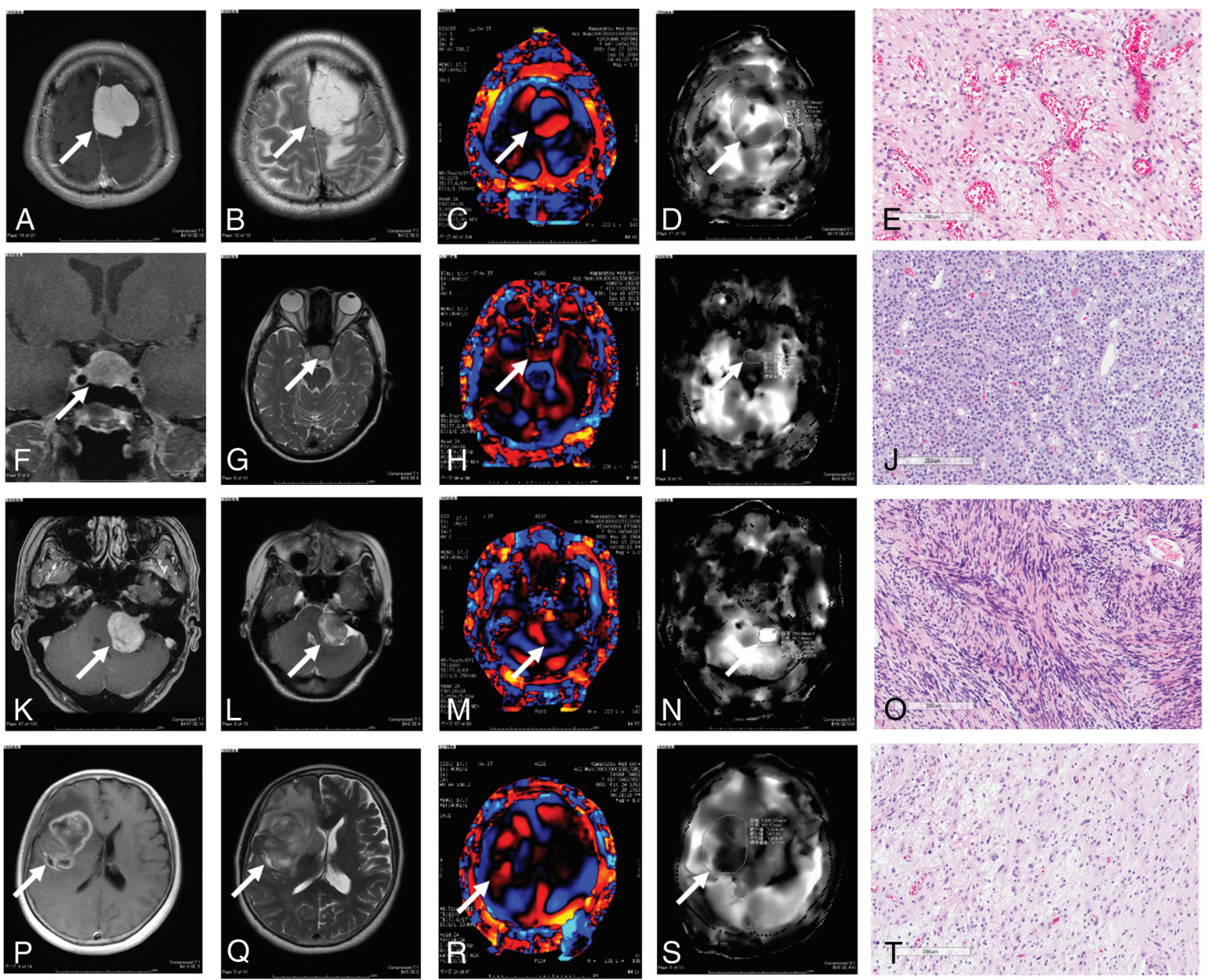

FIG 6. Upper: Left parasagittal meningioma in a 44-year-old woman. A, Axial postcontrast T1-weighted MR imaging shows a strongly enhanced tumor (arrow). B, Axial T2-weighted MR imaging shows a hyperintense tumor (arrow). C, Wave MRE image (arrow). D, Elastogram shows tumor shear stiffness (arrow) $\left(\right.$ mean $\mathrm{SS}=2.1 \mathrm{kPa} ;{ }_{\max } \mathrm{SS}=4.7 \mathrm{kPa}$ ). The intraoperative tumor consistency was intermediate (scale 3). E, Histopathologic examination of the resected tumor indicates meningothelial meningioma (hematoxylin-eosin stain; scale bar, $200 \mu \mathrm{m}$ ). Upper middle: follicle-stimulating hormoneproducing adenoma in a 41-year-old woman. $F$, Axial postcontrast T1-weighted MR imaging shows a weakly enhanced tumor (arrow). G, Axial T2weighted MR imaging shows an isointense tumor (arrow). H, Wave MRE image (arrow). I, Elastogram shows tumor shear stiffness (arrow) (mean SS $=0.9$ $\mathrm{kPa} ; \max _{\mathrm{SS}}=1.1 \mathrm{kPa}$ ). The intraoperative tumor consistency was soft (scale 1). J, Histopathologic examination of the resected tumor indicates diffuse adenoma (hematoxylin-eosin stain; scale bar, $200 \mu \mathrm{m}$ ). Lower middle: Left vestibular schwannoma in a 50-year-old woman. $K$, Axial postcontrast TT-weighted MR imaging shows a strongly enhanced tumor (arrow). L, Axial T2-weighted MR imaging shows a mixed intensity tumor (arrow). M, Wave MRE image (arrow). N, Elastogram shows tumor shear stiffness (arrow) mean $_{\text {mS }}=2.5 \mathrm{kPa} ; \max \mathrm{SS}=3.3 \mathrm{kPa}$ ). The intraoperative tumor consistency was moderate (scale 3). O, Histopathologic examination of the resected tumor indicates a schwannoma with a dominant Antoni A-type region (hematoxylin-eosin stain; scale bar, $200 \mu \mathrm{m})$. Lower: Right insular glioma in a 55-year-old woman. $P$, Axial postcontrast TWI MR imaging shows a ring-enhanced tumor (arrow). Q, Axial T2-weighted MR imaging shows a mixed intensity tumor (arrow). R, Wave MRE image (arrow). S, Elastogram shows tumor shear stiffness (arrow) $\left(_{\text {mean }} \mathrm{SS}=1.5 \mathrm{kPa} ;{ }_{\max } \mathrm{SS}=2.2 \mathrm{kPa}\right)$. The intraoperative tumor consistency was moderate (scale 3). $T$, Histopathologic examination of the resected tumor indicates glioblastoma (hematoxylin-eosin stain; scale bar, $200 \mu \mathrm{m}$ ).

mean $\mathrm{SS}$ and ${ }_{\text {max }} \mathrm{SS}$ with the stiffness grading of all of the intracranial tumors.

In addition, we found a significant difference in the maximum shear stiffness between tumors that were firm (intraoperative tumor consistency scale 4 and 5) and tumors that were nonfirm (intraoperative tumor consistency scale, 1 3). The results suggest that MRE may be able to find firm tumors that may require special care in surgical planning or tumor removal.

In the current study, we demonstrated MRE and histopathologic findings representative of intraoperative firm tumors. In fibrous meningiomas (Fig 7, upper), the shear stiffness correlated with firm consistency intraoperatively. Meningothelial, fibrous, and transitional meningiomas are the most common histopathologic subtypes of meningiomas. ${ }^{19}$ Using MRE, we might differentiate relatively firm meningiomas such as fibrous and transitional meningiomas from relatively soft meningiomas such as meningothelial meningiomas. Most pituitary adenomas are soft and can be easily resected, preserving the tumor capsule by using suction and curettes with transsphenoidal surgery. However, as shown in Fig 7 , lower part, some tumors are firm and fibrous and consequently difficult to resect. In transsphenoidal surgery for such firm pituitary adenomas, excessive maneuvers increase morbidity and mortality related to visual disturbance, panhypophysis, and intraand extracapsular hemorrhage. Although previous studies have 

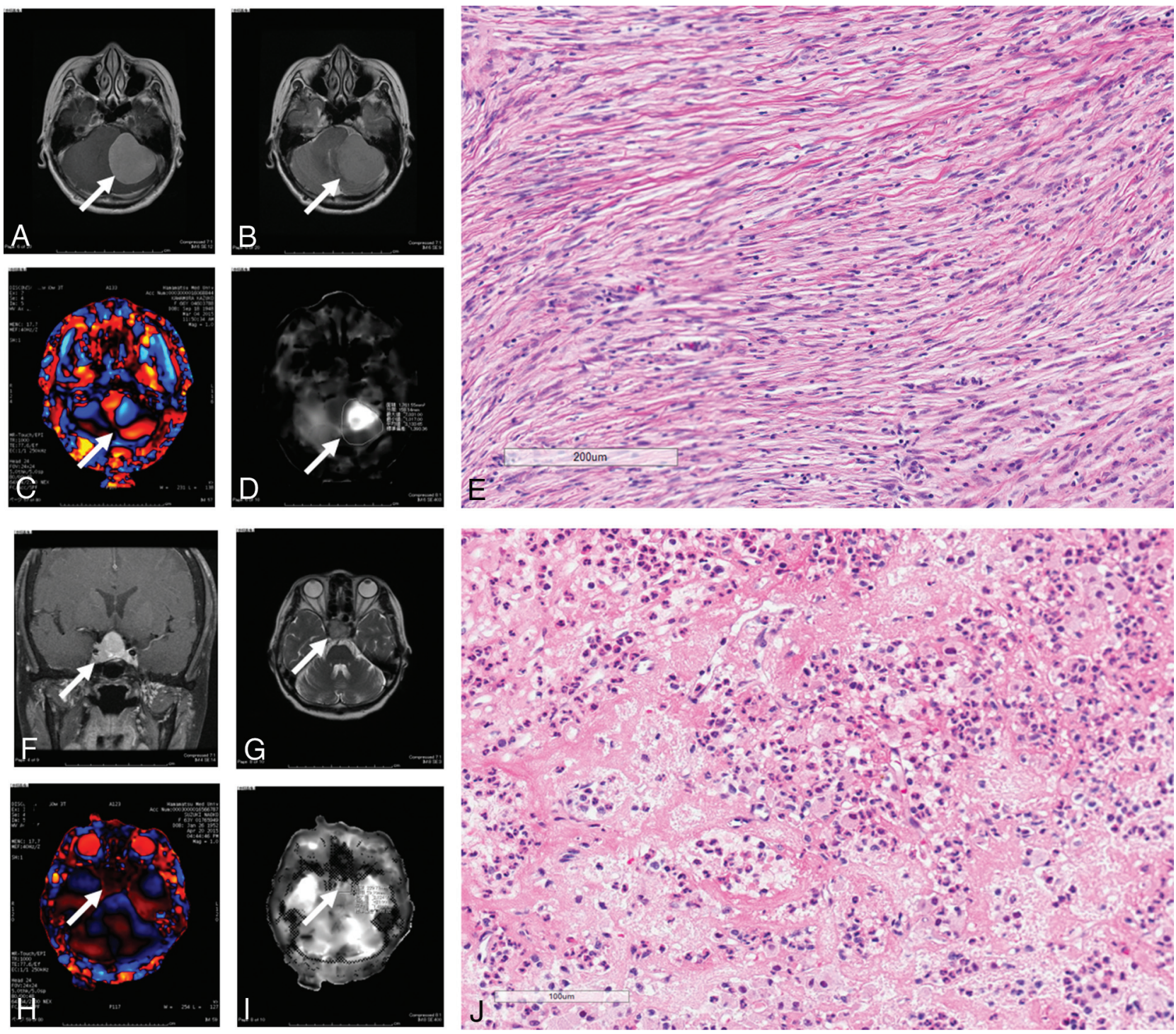

FIG 7. Intraoperative tumors with a firm consistency. Upper: Left cerebellopontine angle meningioma in a 51-year-old man. A, Axial postcontrast T1-weighted MR imaging shows a strongly enhanced tumor (arrow). B, Axial T2-weighted MR imaging shows an isointense tumor (arrow). C, Wave MRE image (arrow). D, Elastogram shows tumor shear stiffness (arrow) (mean $\left.\mathrm{SS}=4.4 \mathrm{kPa} ;{ }_{\max } \mathrm{SS}=7.2 \mathrm{kPa}\right)$. The intraoperative tumor consistency was mostly firm, requiring ultrasonic aspiration at a high setting (scale 4). E, Histopathologic examination of the resected tumor indicates fibrous meningioma (hematoxylin-eosin stain; scale bar, $200 \mu \mathrm{m}$ ). Lower: Nonfunctioning recurrent pituitary adenoma in a 63-year-old woman. F, Axial postcontrast T1-weighted MR imaging shows a strongly enhanced tumor (arrow). G, Axial T2-weighted MR imaging shows an isointense tumor (arrow). $\mathrm{H}$, Wave MRE image (arrow). I, Elastogram shows tumor shear stiffness (arrow) (mean $\mathrm{SS}=1.6 \mathrm{kPa}$; ${ }_{\mathrm{max}} \mathrm{SS}=2.1 \mathrm{kPa}$ ). The intraoperative tumor consistency was mostly firm, requiring ultrasonic aspiration at a high setting (scale 4). J, Histopathologic examination of the resected tumor indicates diffuse adenoma with fibrosis (hematoxylin-eosin stain; scale bar, $200 \mu \mathrm{m}$ ).

attempted to predict the consistency of pituitary adenomas with conventional MR imaging, ${ }^{1}$ diffusion-weighted MR imaging, ${ }^{2}$ and contrast-enhanced 3D FIESTA, ${ }^{3}$ these methods did not directly measure the shear stiffness of pituitary adenomas. To the best of our knowledge, our study is the first to demonstrate the shear stiffness of pituitary adenomas by using MRE.

The consistency of pituitary adenomas depends on the level of fibrosis that correlates with collagenous contents. ${ }^{20}$ MRE might be reflecting the collagenous content of pituitary adenomas. As for vestibular schwannomas, differences in the percentage of the Antoni A component (areas of compact, elongated cells with occasional nuclear palisading) and the Antoni B component (less cellular, with loosely textured cells with indistinct processes and variable lipidization) might determine the shear stiffness. Al- though the preoperative consistency of vestibular schwannoma has not been studied, the difficulties associated with the recently recommended subcapsular tumor dissection for the preservation of facial and cochlear nerve functions in vestibular schwanno$\mathrm{mas}^{21}$ are related to tumor consistency. Therefore, as in transsphenoidal surgery for pituitary adenomas, preoperative assessment of vestibular schwannoma consistency would be recognized as being more important. MRE will be one of the choices in predicting the consistency of vestibular schwannomas preoperatively.

Although most brain MRE studies have been performed by using custom-built transducers in various laboratories worldwide, they have not been approved for their reliability and safety. In our study, we adapted a passive pneumatic driver (MR Touch) 
originally designed for abdominal MRE for introducing shear waves into the brain. Indeed, this was the only commercially available system that could be used for patients in Japan during this study. A higher motion frequency may be useful for superficial tumors, and a lower motion frequency may be useful for deep tumors. In the preliminary study with volunteers, we used the same MEG $(60 \mathrm{~Hz})$ and external driver frequency $(60 \mathrm{~Hz}) \mathrm{re-}$ ported by Murphy et al. ${ }^{13}$ However, we found that an external driver frequency of $60 \mathrm{~Hz}$ was not adequate for our system because the shear waves did not reach the center of the brain. This might be caused by the loose contact between the head and the external driver in our system. With reference to the cross-hatching area, we found that an MEG of $60 \mathrm{~Hz}$, an external driver frequency of $40 \mathrm{~Hz}$, and an amplitude of $50 \%$ were optimal in this system. The precise reason why a MEG frequency that is not equal to the external driver frequency works better is unclear; however, this technique has been widely used in the MRE literature as a means to reduce $\mathrm{TE}^{22}$ or to create broadband sensitivity for multifrequency MRE. ${ }^{23-26}$

Although the spatial resolution in our system was very low because of the low external driver frequency and limited matrix size, the shear stiffness of healthy regions of the brain such as the cerebellum was consistent among patients. Therefore, we used absolute values for both for the mean and maximum shear stiffness (kilopascal) in this study. We speculated that the region with the maximum shear stiffness indicated the region with firm consistency in tumors. However, we observed a case of glioma in which the region with maximum shear stiffness was the center of the cyst in the tumor. Our review of the published literature revealed that the stiffness of the glioma cyst has not been previously reported. The reason for the center of the cyst showing maximum shear stiffness was unclear. Although it is more likely artifacts than anything related to the intracystic pressure, it may be partially explained as follows: Because fluid is a less viscoelastic material, the shear stiffness of the cyst is increased when the intracyst fluid is tensely filled with fluid. Actually, in neurosurgical practice, the tense cyst in tumors is firmer than the surrounding normal brain tissue until it is opened; additionally, when obstructive hydrocephalus is present, the brain surface is firm until ventricular drainage is performed.

The current study had several limitations. First, the spatial resolution of the voxels $(3.75 \mathrm{~mm}$ in-plane and $5 \mathrm{~mm}$ throughplane) used in our study was so coarse that the stiffness presented might include not only tumor tissue but also other surrounding tissue, including brain tissue, bone, and CSF. In a recent study by Murphy et al, ${ }^{23}$ the use of 2-mm, or at most 3-mm, voxels, with the exclusion of the edge pixels from the analysis in ROIs, was recommended because of errors associated with estimating spatial derivatives in the inversion algorithm and also for the minimization of partial-volume effects.

A higher spatial resolution would allow shear stiffness measurements in smaller tumors and provide more accurate regional shear stiffness measurements in large tumors with heterogeneous consistency. To overcome the low spatial resolution of MRE at the single harmonic driver frequency that we used, Sack et $\mathrm{al}^{27}$ at
Charité established a multifrequency MRE to generate high-resolution elastograms..$^{10,11,14,24}$

The recent development of a 3D multislab, multishot acquisition for whole-brain MRE could achieve high signal-to-noise efficacy. ${ }^{25-29} 3 \mathrm{D}$ analysis could improve the results if the wave propagation is complicated, especially if there is throughplane oblique wave propagation that a $2 \mathrm{D}$ analysis would not visualize correctly.

Second, the scaling of tumor consistency in our study involved a qualitative assessment by surgeons at the time of resection; a quantitative assessment of tumor consistency would be preferable. Third, because of the small sample size, we could not examine the histopathologic components corresponding to tumor consistency in detail. The correlation between shear stiffness measured by using MRE and meningioma subtypes, collagenous contents in pituitary adenomas, and heterogeneity of the Antoni pattern in vestibular schwannomas should be investigated in the future.

\section{CONCLUSIONS}

The shear stiffness measured by MRE could be used to evaluate histopathologic subtypes of intracranial tumors. MRE may be useful in the preoperative discrimination of firm tumors.

\section{ACKNOWLEDGMENTS}

The authors thank Masanori Kawate and Kenichi Terashima for their technical assistance.

Disclosures: Naoto Sakai—RELATED: Grant: JSPS KAKENHI (grant No. 15K10359).

\section{REFERENCES}

1. Iuchi T, Saeki N, Tanaka M, et al. MRI prediction of fibrous pituitary adenomas. Acta Neurochir (Wien) 1998;140:779-86 CrossRef Medline

2. Pierallini A, Caramia F, Falcone C, et al. Pituitary macroadenomas: preoperative evaluation of consistency with diffusion-weighted MR imaging_initial experience. Radiology 2006;239:223-31 CrossRef Medline

3. Yamamoto J, Kakeda S, Shimajiri S, et al. Tumor consistency of pituitary macroadenomas: predictive analysis on the basis of imaging features with contrast-enhanced 3D FIESTA at 3T. AJNR Am J Neuroradiol 2014;35:297-303 CrossRef Medline

4. Muthupillai R, Lomas DJ, Rossman PJ, et al. Magnetic resonance elastography by direct visualization of propagating acoustic strain waves. Science 1995;269:1854-57 CrossRef Medline

5. Muthupillai R, Ehman RL. Magnetic resonance elastography. Nat Med 1996;2:601-03 CrossRef Medline

6. Kruse SA, Rose GH, Glaser KJ, et al. Magnetic resonance elastography of the brain. Neuroimage 2008;39:231-37 CrossRef Medline

7. Venkatesh SK, Yin M, Ehman RL. Magnetic resonance elastography of liver: technique, analysis, and clinical applications. J Magn Reson Imaging 2013;37:544-55 CrossRef Medline

8. Murphy MC, Huston J 3rd, Jack CR Jr, et al. Decreased brain stiffness in Alzheimer's disease determined by magnetic resonance elastography. J Magn Reson Imaging 2011;34:494-98 CrossRef Medline

9. Murphy MC, Curran GL, Glaser KJ, et al. Magnetic resonance elastography of the brain in a mouse model of Alzheimer's disease: initial results. Magn Reson Imaging 2012;30:535-39 CrossRef Medline

10. Streitberger KJ, Sack I, Krefting D, et al. Brain viscoelasticity alteration in chronic-progressive multiple sclerosis. PLoS One 2012;7: e29888 CrossRef Medline

11. Streitberger KJ, Wiener E, Hoffmann J, et al. In vivo viscoelastic 
properties of the brain in normal pressure hydrocephalus. $N M R$ Biomed 2011;24:385-92 CrossRef Medline

12. Freimann FB, Streitberger KJ, Klatt D, et al. Alteration of brain viscoelasticity after shunt treatment in normal pressure hydrocephalus. Neuroradiology 2012;54:189-96 CrossRef Medline

13. Murphy MC, Huston J 3rd, Glaser KJ, et al. Preoperative assessment of meningioma stiffness using magnetic resonance elastography. J Neurosurg 2013;118:643-48 CrossRef Medline

14. Streitberger KJ, Reiss-Zimmermann M, Freimann FB, et al. Highresolution mechanical imaging of glioblastoma by multifrequency magnetic resonance elastography. PLoS One 2014;9:e110588 CrossRef Medline

15. Kawaji H, Koizumi S, Sakai N, et al. Evaluation of tumor blood flow after feeder embolization in meningiomas by arterial spin-labeling perfusion magnetic resonance imaging. J Neuroradiol 2013;40: 303-06 CrossRef Medline

16. Sakai N, Koizumi S, Yamashita S, et al. Arterial spin-labeled perfusion imaging reflects vascular density in nonfunctioning pituitary macroadenomas. AJNR Am J Neuroradiol 2013;34:2139-43 CrossRef Medline

17. Sakai N, Yamashita S, Takehara Y, et al. Evaluation of the antiangiogenic effects of octreotide on growth hormone-producing pituitary adenoma using arterial spin-labeling perfusion imaging. Magn Reson Med Sci 2015;14:73-76 CrossRef Medline

18. Koizumi S, Sakai N, Kawaji H, et al. Pseudo-continuous arterial spin labeling reflects vascular density and differentiates angiomatous meningiomas from non-angiomatous meningiomas. Neurooncol 2015;121:549-56 CrossRef Medline

19. Louis DN, Ohgaki H, Wiestler OD, et al. The 2007 WHO classification of tumours of the central nervous system. Acta Neuropathol 2007;114:97-109 CrossRef Medline

20. Naganuma H, Satoh E, Nukui H. Technical considerations of transsphenoidal removal of fibrous pituitary adenomas and evaluation of collagen content and subtype in the adenomas. Neurol Med Chir (Tokyo) 2002;42:202-12 CrossRef Medline

21. Sasaki T, Shono T, Hashiguchi K, et al. Histological considerations of the cleavage plane for preservation of facial and cochlear nerve functions in vestibular schwannoma surgery. J Neurosurg 2009;110: 648-55 CrossRef Medline

22. Shinagawa Y, Mitsufuji T, Morimoto S, et al. Optimization of scanning parameters for MR elastography at 3.0 $\mathrm{T}$ clinical unit: volunteer study. Japan J Radiol 2014;32:441-46 CrossRef Medline

23. Murphy MC, Huston J 3rd, Jack CR Jr, et al. Measuring the characteristic topography of brain stiffness with magnetic resonance elastography. PLoS One 2013;8:e81668 CrossRef Medline

24. Dittmann F, Hirsch S, Tzschätzsch $H$, et al. In vivo wideband multifrequency MR elastography of the human brain and liver. Magn Reson Med 2015 Oct 20. [Epub ahead of print] CrossRef Medline

25. Garteiser P, Sahebjavaher RS, Ter Beek LC, et al. Rapid acquisition of multifrequency, multislice and multidirectional MR elastography data with a fractionally encoded gradient echo sequence. $N M R$ Biomed 2013;26:1326-35 CrossRef Medline

26. Rump J, Klatt D, Braun J, et al. Fractional encoding of harmonic motions in MR elastography. Magn Reson Med 2007;57:388-95 CrossRef Medline

27. Sack I, Beierbach B, Hamhaber U, et al. Non-invasive measurement of brain viscoelasticity using magnetic resonance elastography. NMR Biomed 2008;21:265-71 CrossRef Medline

28. Yin Z, Kearney SP, Magin RL, et al. Concurrent 3D acquisition of diffusion tensor imaging and magnetic resonance elastography displacement data (DTI-MRE): theory and in vivo application. Magn Reson Med 2016 Jan 20. [Epub ahead of print] CrossRef Medline

29. Johnson CL, Holtrop JL, McGarry MD, et al. 3D multislab, multishot acquisition for fast, whole-brain MR elastography with high signalto-noise efficiency. Magn Reson Med 2014;71:477-85 CrossRef Medline 